\title{
The comparison of the effect of double and flat pyramid training methods on hypertrophy and muscular strength of male power-lifters
}

Mohammad Rasekh ${ }^{\mathrm{BCDE}}$, Ramin Shabani ${ }^{\mathrm{AE}}$

Department of Exercise Physiology, Rasht Branch, Islamic Azad University, Rasht, Iran

Authors' Contribution: A -Study design; B -Data collection; C -Statistical analysis; D -Manuscript Preparation; E Funds Collection

$\begin{array}{ll}\begin{array}{l}\text { Abstract } \\ \text { Background } \\ \text { and Study Aim }\end{array} & \begin{array}{l}\text { Resistance training is considered as the most effective method to increase muscle strength and mass. The } \\ \text { present study aimed to compare the effect of a double pyramid and a flat pyramid training methods on } \\ \text { hypertrophy and muscular strength of male power-lifters. }\end{array} \\ \begin{array}{l}\text { Material and } \\ \text { Methods }\end{array} & \begin{array}{l}\text { Thirty students (age } 21.40 \pm 1.71 \text { years) were randomly assigned to three groups of double pyramid training } \\ \text { (10 subjects), flat pyramid training (10 subjects), and the control trained by the traditional method (10 } \\ \text { subjects). The experimental groups were trained three sessions a week for eight weeks whereas the control } \\ \text { group continued their ordinary training program in the traditional method two sessions a week. Before } \\ \text { and after the training, the muscular strength index was measured by bench press, leg press, and deadlift } \\ \text { and the muscle volume was determined in their chest, arm, and thigh. Data were statistically examined by } \\ \text { the analysis of variance and paired test in the SPSS (ver. 21) software package. The significance level was } \\ \text { set at the P<0.05 level. } \\ \text { Significant differences were observed among the studied groups in the variables of bench press, leg press, } \\ \text { and deadlift, as well as in the variables of arm volume, chest volume, and thigh volume (P }<0.05) \text {. Bench } \\ \text { press, leg press, deadlift, and the volume of arm, chest, and thigh were increased significantly from the } \\ \text { pretest to the posttest in all three groups }(\mathrm{P}<0.001) .\end{array} \\ \text { Results } & \begin{array}{l}\text { A double and flat pyramid training period has similar positive impacts on muscular strength and volume } \\ \text { of power-lifters. } \\ \text { powerlifting, double pyramid training, flat pyramid training, muscular strength, muscle volume }\end{array} \\ \text { Conclusions: } & \end{array}$

\section{Introduction}

Power-lifting is a strength exercise composed of three practices: squat, bench press, and deadlift. Besides muscle volume, an important item in powerlifting is maximal power which is the chief parameter of muscle fitness for optimal implementation of sporting skills such as jumping, speeding, and direction shift. When the goal of a resistance training program is to increase the maximal strength, the training load (intensity) will be one of the most important variables in designing the training program [1]. Given the physiological principles for the use of maximum loads to increase strength, the maximum loads can essentially stimulate and retrieve all motor units including fast-twitch and slow-twitch [2]. As such, Häkkinen et al. [3] reported that the use of a maximal load of $80-85 \%$ of one repetition maximum (1RM) is of crucial significance to achieve optimal consistencies in the muscular strength of the trained people. In addition, training volume and intensity are the main variables in resistance training. Preceding research has shown that changes in training volume influence neural, hormonal, hypertrophic, and metabolic responses [4].

In the literature on strength training, the impact of traditional (linear) loading pattern has been extensively subject to research. It is composed of three cycles. In each cycle, the training initially has a high volume and a moderate intensity followed by an increase in

(c) Mohammad Rasekh, Ramin Shabani, 2021

doi:10.15561/20755279.2021.0203 the intensity and a decrease in volume as the training progresses [5]. In contrast, the nonlinear pattern is composed of short-term high-volume periods and is based on the sinuous manipulation of the training volume and intensity $[6,7]$. Most research has focused on the effect of traditional training [8]. Nonetheless, the impacts of sinuous nonlinear training patterns, especially flat and double pyramid methods, have not been compared adequately yet. In this respect, the most common training protocols to increase power and hypertrophy are to use a fixed load at each set of a flat pyramid loading pattern and to progressively increase the training load from one set to the next in a double pyramid loading pattern [9, 10]. It has been documented that flat pyramid loading patterns to achieve the maximum strength (maximum power) are accompanied by a slight increase in muscle volume (hypertrophy) and creates the highest level of neural consistency. So, it is superior over the other loading patterns in increasing the maximum power [11]. In contrast, double pyramid patterns impose high pressure and it seems to further increase muscle volume [12, 13]. Some research has shown that resistance training with more sets would perform better $[13,14]$. In a study on weight-lifters, Rhea et al. [15] found that the three-set resistance training outperformed the one-set training in enhancing strength. Similarly, Kelly et al. [16] reported that after eight weeks of resistance training, the strength in knee extension was increased only in the training group with more sets whereas no significant increase was 
observed in strength in the training group with fewer sets.

Despite a wealth of research in this field, there is a broad gap in the published literature as to the role of training variables in increasing muscular power and volume. However, relatively few studies have focused on muscular adaptation in response to different loading methods. So, given the contradictory and ambiguous results, the present study aimed to shed light on the effect of resistance training with two different methods in muscular power and hypertrophy parameters in male power-lifting athletes.

\section{Materials and Methods}

Participants. The statistical population was composed of power-lifters of a selected club in the city of Rasht, Iran of whom 30 students (age $21.40 \pm 1.71$ years) were randomly assigned to three 10-individual groups for the double pyramid, flat pyramid, and control. Muscular power parameters and volume were measured before and after the training sessions. The inclusion criteria included that the athletes should have been trained in bodybuilding at a rate of three sessions a week for at least 12 months and they should not have taken any supplements or anabolic steroids.

Research design. The control group kept their ordinary training in the traditional method two sessions a week. The research was conducted in accordance with the Declaration of Helsinki and was approved by the
Ethics Committee of the Islamic Azad University, Rasht approved. Ethic's code was IR. IAU. RASHT. REC. 1399. 014 . The sample size was determined by the $\mathrm{G}$ power (Ver. 3. 1. 9. 2) software package to be 28 specified for ANOVA at the error level of $\alpha=0.05$ and $\beta=0.80$, but it was increased to 30 individuals to have the same number of subjects in each group.

The resistance training program was implemented three sessions a week for eight weeks (Tables 1 and 2). So, two training protocols were developed. The flat pyramid training method was performed in nine movements in seven consecutive sets at an intensity of $80-100 \%$ of 1RM. The double pyramid training was conducted in nine movements in eight consecutive sets at an intensity of 80$100 \%$ of $1 \mathrm{RM}[1,12,17,18]$.

Measurement: The height and weight of the subjects were measured with a Seca measurement device in $\mathrm{kg}$. The maximum power of the subjects was measured using $1 \mathrm{RM}$ by the method of McGowan and colleagues [19]. The muscular power (maximum strength) was measured by three movements of bench press with a barbell, squat with a barbell, and deadlift. In these three tests, the number of movements was recorded for each subject based on the weight in $\mathrm{kg}$ and Equation was used to calculate 1RM. Also, the muscle volume was measured by the anthropometry method for the muscles of the chest, thigh, and gluteal muscles using an inelastic tape made in China $[18,19]$.

Table 1. Flat pyramidal training protocol

\begin{tabular}{|c|c|c|c|c|c|}
\hline Week & Flat pyramidal training & $\begin{array}{l}\text { Rest } \\
\text { (second) }\end{array}$ & Sets & Repeat & Intensity \\
\hline $1-4$ & $\begin{array}{l}\text { Barbell chest press, Triceps, } \\
\text { Barbell Bent-over Row, } \\
\text { Barbell Full Squat, Dedlifte, } \\
\text { Standing Barbell Curl, Close } \\
\text { Grip Bench Press, seated } \\
\text { barbell millitary press,leg } \\
\text { curl, Standing Machine Calf } \\
\text { Raise }\end{array}$ & 180 & 7 & $6-3-3-3-3-3-6$ & $80-90 \%$ \\
\hline $5-8$ & & 180 & 7 & $1-2-3-4-5$ & $90-100 \%$ \\
\hline
\end{tabular}

Table 2. Double pyramidal training protocol

\begin{tabular}{|c|c|c|c|c|c|}
\hline Week & $\begin{array}{l}\text { Double pyramidal } \\
\text { training }\end{array}$ & $\begin{array}{l}\text { Rest } \\
\text { (second) }\end{array}$ & Sets & Repeat & Intensity \\
\hline $1-4$ & $\begin{array}{l}\text { Barbell chest press, } \\
\text { Triceps, Barbell Bent- } \\
\text { over Row, Barbell } \\
\text { Full Squat, Dedlifte, } \\
\text { Standing Barbell Curl, } \\
\text { Close Grip Bench } \\
\text { Press, seated barbell } \\
\text { millitary press,leg curl, } \\
\text { Standing Machine Calf } \\
\text { Raise }\end{array}$ & 180 & 8 & $4-3-2-1-1-2-3-4$ & $80-90 \%$ \\
\hline $5-8$ & & 180 & 8 & $4-3-2-1-1-2-3-4$ & $90-100 \%$ \\
\hline
\end{tabular}


Statistical Analysis. One-way analysis of variance (ANOVA) was used for between-group comparison and the correlated t-test was applied to check the statistical significance of pretest and posttest at the $\mathrm{P}<0.05$ level. All statistical operations were performed in the SPSS software package.

\section{Results}

According to Table 3, significant increases were observed in the bench press, leg press, deadlift, arm volume, and chest volume in all three groups of the flat pyramid, double pyramid, and control after the intervention $(\mathrm{P}=0.001)$.

According to the results of the one-way ANOVA, the three studied groups differed significantly $(\mathrm{P}<0.05)$ in the bench press, leg press, deadlift, arm volume, and chest volume.

\section{Discussion}

The results revealed significant increases in the variables of muscular strength and the number of bench press, leg press, and deadlift in the experimental groups. Our uttermost finding is the equal increase in upper-body and lower-body strength in the flat and double pyramid protocols after eight weeks of training. Since the training volume and load were the same in the two protocols, this finding was not unexpected.

Several studies have reported similar increases in the strength when the volume was kept constant in different resistance training protocols. In this respect, Chestnut et al. [20] reported that in both training groups with equal volume and different training zone of 4RM (six sets with four repetitions until failure in each set) and 10RM (three sets with 10 repetitions until failure in each set), similar increases were achieved in 1RM strength of forearm flexors, movement power of forearm flexors

Table 3. Changes of Research Variables Groups Before and After 8 Weeks of Resistance Training

\begin{tabular}{|c|c|c|c|c|c|}
\hline Variables & Group & Baseline & Post -test & Paired-test $^{a}$ & ANOVA $^{b}$ test \\
\hline \multirow[t]{3}{*}{ Weight (kg) } & Dual pyramidal & $79.90 \pm 2.68$ & $80.91 \pm 2.66$ & $0.001^{*}$ & 0.055 \\
\hline & Flat pyramidal & $84.80 \pm 2.52$ & $83.80 \pm 2.50$ & $0.001^{*}$ & \\
\hline & Control & $84.60 \pm 2.50$ & $84.80 \pm 2.41$ & $0.001^{*}$ & \\
\hline \multirow[t]{3}{*}{ chest press } & Dual pyramidal & $71.20 \pm 1.32$ & $73.40 \pm 1.43$ & $0.001 *$ & $0.001 *$ \\
\hline & Flat pyramidal & $69.40 \pm 1.56$ & $71.60 \pm 5.16$ & $0.001^{*}$ & \\
\hline & Control & $72.00 \pm 1.38$ & $72.95 \pm 1.45$ & $0.001^{*}$ & \\
\hline \multirow[t]{3}{*}{ leg press } & Dual pyramidal & $107.50 \pm 3.00$ & $113.0 \pm 3.09$ & $0.001^{*}$ & $0.001^{*}$ \\
\hline & Flat pyramidal & $116.0 \pm 2.56$ & $121.20 \pm 2.59$ & $0.001^{*}$ & \\
\hline & Control & $114.0 \pm 3.05$ & $117.0 \pm 3.0$ & $0.001^{*}$ & \\
\hline \multirow[t]{3}{*}{ dead lift } & Dual pyramidal & $52.60 \pm 1.91$ & $55.10 \pm 1.85$ & $0.001^{*}$ & $0.001^{*}$ \\
\hline & Flat pyramidal & $53.0 \pm 1.30$ & $57.70 \pm 1.25$ & $0.001^{*}$ & \\
\hline & Control & $51.30 \pm 1.38$ & $52.20 \pm 1.38$ & $0.001 *$ & \\
\hline \multirow[t]{3}{*}{ Arm volume } & Dual pyramidal & $37.90 \pm 0.48$ & $38.70 \pm 0.42$ & $0.001^{*}$ & $0.001^{*}$ \\
\hline & Flat pyramidal & $38.40 \pm 0.54$ & $39.25 \pm 0.54$ & $0.001^{*}$ & \\
\hline & Control & $37.70 \pm 0.47$ & $38.05 \pm 0.47$ & $0.001^{*}$ & \\
\hline \multirow[t]{3}{*}{ chest volume } & Dual pyramidal & $101.10 \pm 0.86$ & $102.10 \pm 0.88$ & $0.001^{*}$ & $0.001 *$ \\
\hline & Flat pyramidal & $102.30 \pm 0.94$ & $103.05 \pm 0.88$ & $0.001 *$ & \\
\hline & Control & $102.40 \pm 0.84$ & $102.70 \pm 0.77$ & $0.001^{*}$ & \\
\hline \multirow[t]{3}{*}{ Hip volume } & Dual pyramidal & $65.20 \pm 0.69$ & $66.10 \pm 0.65$ & $0.001^{*}$ & $0.001^{*}$ \\
\hline & Flat pyramidal & $64.50 \pm 0.73$ & $65.50 \pm 0.77$ & $0.001^{*}$ & \\
\hline & Control & $63.90 \pm 1.0$ & $64.45 \pm 0.99$ & $0.001^{*}$ & \\
\hline
\end{tabular}

$\mathrm{cm}=$ centimetres, $\mathrm{kg}=$ kilograms, \% = percent, $\mathrm{s}=$ seconds, $\mathrm{m}=$ metres, $\mathrm{r}=$ repeat; $\mathrm{BMI}:$ Body mass index, ${ }^{*}$ significant $\mathrm{p}$-value $(\mathrm{p}=<0.05) ;{ }^{\text {a }}$ paird t-test,${ }^{\mathrm{b}}$ ANOVA test 
and extensors, and muscle size in the untrained subjects after 10 weeks of resistance training. Larson found that the muscular power of both groups was increased in each training session after two weeks of resistance training [21]. The increase in the hip power of the resistance training group was significant, but the two groups did not differ significantly in the shoulder press. In addition, Bakhtjerdi et al- [22] examine the traditional and TRX training programs and revealed that the maximum leg power was increased in both groups after each station. Also, the thigh cross-sectional area was increased in both groups, although the increase was greater in the traditional training group than in the TRX group.

Although the two training protocols had various loading methods, both protocols used the maximum loads to increase the strength. In this respect, it can be said that when maximum loads and fewer repetitions are used, the retrieval of fast-twitch motor units and the exertion of pressure on the neuromuscular system change the neural activity of the muscle, thereby increasing muscular strength [23]. In contrast, Ghigiarelli et al. showed that the bench press strength with intensity of $60-70 \%$ of $1 \mathrm{RM}$ did not change significantly although it was higher in the training group [24]. In addition, Zourdos et al. [23] compared the effect of modified and traditional resistance training programs on hypertrophy in 1820 -year-old male body-building students and found that hypertrophy did not differ between the groups significantly.

The possible reasons for the inconsistency with our research are the training protocol and the age of the subjects as we used two types of pyramid training whereas they used traditional training and bench press.

Changes in muscular power and size after resistance training are likely to be accompanied by an increase in the size of muscular fibers and the conversion of motor units or phenotype. Beside the increase in the cross-section of muscular fibers in resistance training, changes happen in the isoforms of the myosin heavy chain from the fasttwitch fibers type IIb to the fast-twitch fibers type IIa. Overall, the increase in muscular strength is more related to the hypertrophy of the fast-twitch muscle fibers.

With respect to the variable of hypertrophy, significant increases were revealed in arm volume, chest volume, and thigh volume in the flat and double resistance training groups. Bakhtajerdi et al. [21] reported that the thigh cross-section increased in both groups, but the increase was greater in the traditional group than in the TRX group. Zoudros et al. [23] did not find any significant differences between the groups in hypertrophy in squat and deadlift, whilst the traditional resistance training group had higher chest hypertrophy. Schoenfeld et al. [25] showed that after eight weeks, no significant differences appeared in the hypertrophy of biceps muscles, but the changes in the hypertrophy after bench press and squad were significant. On the contrary, Nezami et al. [26] found that the participants subjected to the pyramid method had higher triceps brachial strength and size than those subjected to the flat pyramid method, but the increase was not statistically significant. They reported that the capacity to produce the maximum force in a muscle is determined in the first place by the simultaneous contraction of muscular sarcomeres. The increase in strength during resistance training can be expected to relate to the increase in muscle size [26].

O'Shea et al. [27] studied the effect of a six-week training program in two groups - a low-volume group and a high-volume group on 30 students and found that despite the increase in the volume of thigh muscle in both groups, there was not a significant difference between them. The inconsistency of these studies with our findings can be attributed to the type of training protocols (both resistance training with different volumes and flat pyramid training in study of O'Shea et al. comparing to versus double and flat training methods in our research) and subjects (novice versus athletes of power-lifting).

There are several mechanisms for the impact of training on increasing hypertrophy. Hypertrophy induced by a workout in resistance training methods often results in an increase in sarcomeres and at the same time, an increase in myofibrils [28]. All in all, these events increase the diameter of single muscular fibers and consequently, enlarge the cross-section. The second training mechanism represents the length of muscular fibers. It has been documented that the length of muscular fibers increases both in old and young people after high-intensity resistance training. Indeed, the increase bring about an increase in the generation of maximum power [29].

Based on the preceding research, the use of moderate to heavy loads at moderate to high repetitions is considered a high-volume program. This sort of training is regarded as a resistance program for muscle volume.

\section{Conclusions}

In our research, although no definite reason can be put forth for the different responses of upper-body and lowerbody muscles to the two training protocols, the low number of the subjects in the training groups can be nominated as a major cause. So, it seems that the use of a similar mechanism for stimulating the neuromuscular system has led to similar initial neuromuscular adaptations by the two different protocols. On the other hand, six weeks of initial resistance training at the hypertrophy stage might have influenced the increase in the strength by the two protocols greatly.

According to the results, a double or flat pyramid training program can by itself influence the strength and muscular hypertrophy of power-lifters significantly.

\section{Acknowledgments}

We gratefully acknowledge the contribution of the study participants.

\section{Author Contributions}

Mohammad Rasekh contributed to the collection, analysis, and interpretation of the data. Ramin Shabani designed and coordinated the research. All authors revised the manuscript and gave their contribution to improve the paper. 


\section{References}

1. Tan B. Manipulating Resistance Training Program Variables to Optimize Maximum Strength in Men: A Review. Journal of Strength and Conditioning Research, 1999;13:289-304. https://doi.org/10.1519/00124278-199908000-00019

2. Henry T. Resistance training for judo: functional strength training concepts and principles. Journal of Strength and Conditioning Research, 2011;33 (6):40-9. https://doi.org/10.1519/SSC.0b013e31823a6675

3. Häkkinen $\mathrm{K}$, Alen $\mathrm{M}$, Komi $\mathrm{P}$. Changes in isometric force-and relaxation-time, electromyographic and muscle fibre characteristics of human skeletal muscle during strength training and detraining. Acta Physiologica Scandinavica, 1985;125 (4):573-85. https://doi.org/10.1111/j.1748-1716.1985.tb07760.x

4. Schuenke MD, Herman JR, Gliders RM, Hagerman FC, Hikida RS, Rana SR, et al. Early-phase muscular adaptations in response to slow-speed versus traditional resistance-training regimens. European Journal of Applied Physiology, 2012;112 (10):3585-95. https://doi.org/10.1007/s00421-012-2339-3

5. Prestes J, Frollini AB, de Lima C, Donatto FF, Foschini $\mathrm{D}$, de Cássia Marqueti $\mathrm{R}$, et al. Comparison Between Linear and Daily Undulating Periodized Resistance Training to Increase Strength. Journal of Strength and Conditioning Research, 2009;23:2437-42. https://doi.org/10.1519/JSC.0b013e3181c03548

6. Hoffman JR, Ratamess NA, Klatt M, Faigenbaum AD, Ross RE, Tranchina NM, et al. Comparison between different off-season resistance training programs in Division III American college football players. Journal of Strength and Conditioning Research, 2009;23 (1):11-9. https://doi.org/10.1519/jsc.0b013e3181876a78

7. Baker D, Wilson G, Carlyon R. Periodization: The effect on strength of manipulating volume and intensity. Journal of Strength and Conditioning Research, 1994;8 (4):235-42. https://doi.org/10.1519/1533-4287(1994)008

8. Rhea MR, Alderman BL. A meta-analysis of periodized versus nonperiodized strength and power training programs. Research Quarterly for Exercise and Sport, 2004;75 (4):413-22. https://doi.org/10.1080/02701367.2004.10609174

9. Razmjou S, Rajabi H, Jannati M, Azizi M, Jahandideh A. The effects of Delorme and oxford techniques on serum cell injury indices and growth factor in untrained women. World Journal of Sport Sciences, 2010;3 (1):44-52. https://doi.org/10.1177/2164956120912849

10.Angleri V, Ugrinowitsch C, Libardi C. Are resistance training systems necessary to avoid a stagnation and maximize the gains muscle strength and hypertrophy? Science \& Sports, 2020;35 (2):65. https://doi.org/10.1016/j.scispo.2018.12.013

11.Fleck SJ, Kraemer W. Designing resistance training programs. Human Kinetics; 2014.

12.Bompa TO, Di Pasquale M, Cornacchia L. Serious strength training. Human Kinetics; 2012.

13. Mangine GT, Hoffman JR, GonzalezAM, Townsend JR, Wells AJ, Jajtner AR, et al. The effect of training volume and intensity on improvements in muscular strength and size in resistancetrained men. Physiological Reports, 2015;3 (8):e12472. https://doi.org/10.14814/phy2.12472

14.Schoenfeld BJ, Contreras B, Krieger J, Grgic J, Delcastillo $\mathrm{K}$, Belliard $\mathrm{R}$, et al. Resistance training volume enhances muscle hypertrophy but not strength in trained men. Medicine and Science in Sports and Exercise, 2019;51 (1):94-103. https://doi.org/10.1249/MSS.0000000000001764
15. Rhea MR, Alvar BA, Ball SD, Burkett LN. Three sets of weight training superior to 1 set with equal intensity for eliciting strength. The Journal of Strength \& Conditioning Research, 2002;16 (4):525-9. https://doi.org/10.1519/00124278-200211000-00006

16.Kelly SB, Brown LE, Coburn JW, Zinder SM, Gardner LM, Nguyen D. The effect of single versus multiple sets on strength. Journal of Strength and Conditioning Research, 2007;21 (4):1003-6. https://doi.org/10.1519/00124278-200711000-00003

17.Rønnestad BR, Egeland W, Kvamme NH, Refsnes PE, Kadi F, Raastad T. Dissimilar effects of one-and threeset strength training on strength and muscle mass gains in upper and lower body in untrained subjects. Journal of Strength and Conditioning Research, 2007;21 (1):157-63. https://doi.org/10.1519/0012427820070200000028

18.Housh DJ, Housh TJ, Weir JP, Weir LL, Johnson GO, Stout JR. Anthropometric estimation of thigh muscle cross-sectional area. Medicine \& Science in Sports \& Exercise, 1995;27 (5):784-91. https://doi.org/10.1249/00005768-199505000-00023

19. Frisancho AR. T riceps skin fold and upper arm muscle size norms for assessment of nutritional status. The American Journal of Clinical Nutrition, 1974;27 (10):1052-8. https://doi.org/10.1093/ajcn/27.8.1052

20.Chestnut JL, Docherty D. The effects of 4 and 10 repetition maximum weight-training protocols on neuromuscular adaptations in untrained men. Journal of Strength and Conditioning Research, 1999;13 (4):353-9. https://doi.org/10.1519/1533-4287(1999)013<0353:TEOAR $\mathrm{M}>2.0 . \mathrm{CO} ; 2$

21.Larsson O. A comparison of two short training programs, strength versus hypertrophy, to increase thelRM in two different upper body exercises. [dissertation on the internet]. 2016. [cited 2020 Dec 7]. Available from: http://urn.kb.se/ resolve?urn=urn:nbn:se:hh:diva-31887

22.Mokaram Bakhtajerdi J, Moghadasi M. Effects of Heavy Duty versus traditional resistance training on thigh muscle cross-sectional area. Journal of Physical Activity and Hormones, 2018;2 (2):13-28. https://doi.org/10.1007/ s00421-009-1307-z

23.Zourdos MC, Jo E, Khamoui AV, Lee S-R, Park B-S, Ormsbee MJ, et al. Modified daily undulating periodization model produces greater performance than a traditional configuration in powerlifters. Journal of Strength and Conditioning Research, 2016;30 (3):784-91. https://doi.org/10.1519/JSC.0000000000001165

24.Ghigiarelli JJ, Pelton LM, Gonzalez AM, Fulop AM, Gee JY, Sell KM. Effects of a 6-Week Bench Press Program Using the Freak Bar in a Sample of Collegiate Club Powerlifters. Journal of Strength and Conditioning Research, 2018;32 (4):938-49. https://doi.org/10.1519/JSC.0000000000002430

25. Schoenfeld BJ, Grgic J. Does training to failure maximize muscle hypertrophy? Journal of Strength and Conditioning Research, 2019;41 (5):108-13. https://doi.org/10.1519/SSC.0000000000000473

26.Nezami S, Samavati Sharif MA, Chezani Sharahi A. The Comparison of the Effects of Two Types of Resistance Training on Triceps Brachial Thickness and its Connection with Maximum Strength in Novice Bodybuilders. Journal of Sport Biosciences, 2016;8 (2):207-19. https://doi.org/10.22059/jsb.2016.59096

27.O'Shea P. Effects of selected weight training programs on the development of strength and muscle hypertrophy. Research Quarterly American Association for Health, 
Physical Education and Recreation, 1966;37 (1):95-102. https://doi. org/10.1080/10671188.1966.10614741

28. Reeves ND, Narici MV, Maganaris CN. In vivo human muscle structure and function: adaptations to resistance training in old age. Experimental Physiology, 2004;89 (6):675-89. https://doi.org/10.1113/expphysiol.2004. 027797
29. Toigo M, Boutellier U. New fundamental resistance exercise determinants of molecular and cellular muscle adaptations. European Journal of Applied Physiology, 2006;97 (6):64363. https://doi.org/10.1007/s00421-006-0238-1

\section{Information about the authors:}

Mohammad Rasekh; https://orcid.org/0000-0003-3678-3468; mohammad_rasekh83@yahoo.com; Department of Exercise Physiology, Rasht Branch, Islamic Azad University; Rasht, Iran.

Ramin Shabani; (Corresponding author) ; Associate Professor; https://orcid.org/0000-0002-2681-3814; Shabani_msn@yahoo. com; Department of Exercise Physiology, Rasht Branch, Islamic Azad University; Rasht, Iran.

Cite this article as:

Rasekh M, Shabani R. The comparison of the effect of double and flat pyramid training methods on hypertrophy and muscular strength of male power-lifters. Physical Education of Students, 2021;25(2):92-97. https://doi.org/10.15561/20755279.2021.0203

This is an Open Access article distributed under the terms of the Creative Commons Attribution License, which permits unrestricted use, distribution, and reproduction in any medium, provided the original work is properly cited http://creativecommons.org/licenses/by/4.0/deed.en

Received: 25.01 .2021

Accepted: 10.03.2021; Published: 30.04.2021 